\title{
Quantification of CTOD fracture toughness in welded joints to evaluate the efficacy of vibration stress relief compared to thermal stress relief
}

\author{
Amauri Gomes de Moraes ${ }^{a *}$ (D), Thomas Gabriel Rosauro Clarke ${ }^{a}$ Igor Luís Diehl \\ ${ }^{a}$ Universidade Federal do Rio Grande do Sul-UFRGS, Departamento de Engenharia Metalúrgica, \\ Porto Alegre, RS, Brasil
}

Received: April 16, 2020; Revised: July 22, 2020; Accepted: August 04, 2020

\begin{abstract}
Resonant vibration residual stress relief (R-VSR) is an alternative method to post-weld heat treatments (PWHT) which is said to lead to less distortion and lower costs. The method of superposition of cyclic stresses and residual stresses, which can lead to localized yielding of the material, dislocation movement and subsequent stress relief. This article aims at investigating the efficiency of resonant vibration in the relief of residual stresses in welded joints of HSLA Domex700 steel sheets. Mechanical stress relief was compared to a common PWHT, and stress levels were then quantified through X-ray diffraction. Samples were also characterized by CTOD fracture toughness tests, fractographic analysis and tensile tests. Results indicate that the mechanical method was significantly less effective in relieving stresses in comparison with the PWHT, but led to apparent improvements in fracture toughness and in tensile tests. FWHM values indicated significant distortion for PWHT and less distortion for R-VSR.
\end{abstract}

Keywords: Resonant mechanical vibration, residual stresses, $x$-ray diffraction, fracture toughness-ctod.

\section{Introduction}

It is well-known that welding generates substantial residual stress due to expansion and contraction restrictions resulting from the inhomogeneous temperature distribution, temperature gradients and microstructural features of the welded metal ${ }^{1,2}$. Leggatt ${ }^{3}$ also points to the influence of the previous residual stress distribution and geometry of the component, and Totten ${ }^{4}$ includes phase transformations as another factor.

It is known that excessive levels of residual stresses can lead to shorter life cycles due to poor fatigue resistance ${ }^{5,6}$. Furthermore, residual tensile stresses are not desirable because they contribute to premature failures, and influence mechanisms of stress corrosion, fatigue and failure due to distortion and change in dimensional stability ${ }^{5-8}$.

According to Kwofie ${ }^{9}$ and Baqar et al. ${ }^{10}$, the use of PWHT to relieve residual stresses is effective, but is limited by the high cost of the equipment and the amount of energy and time consumed. The generation of oxide shell is also problematic. Plastic deformation-induced stress relief during PWHT can be analytically expressed as the change in the elastic deformation limit measured in terms of material yield strength $^{11}$. The PWHT produces stress relief due to dislocation substructure rearrangement which reduces the elastic limit of the material ${ }^{12}$, and according to Chuvas et al. ${ }^{13}$, relieves the tractive and compressive residual stresses in the welded joint. Mechanical properties such as ultimate tensile strength and hardness have been reported to be reduced after post weld heat treatment process ${ }^{14}$.

According to Aoki et al. ${ }^{15,16}$ and Adams et al. ${ }^{17}$, stress relieving methods using mechanical vibration, which can be harmonic (resonant) waves with different amplitudes, cause

*e-mail: amaurihkd@gmail.com a combination of dynamic loads and residual stresses, which could lead to the occurrence of plastic flow.

Applying the method of residual stress relief by resonant mechanical vibration (R-VSR) is justified because it would have great economic and environmental advantages due to the relatively lower energy consumption and higher productivity achieved compared to conventional post-weld heat treatments ${ }^{18}$. It is therefore important to evaluate its efficiency in relieving residual stresses. It would also be interesting to understand the behavior of fracture toughness, using the crack tip opening displacement (CTOD) parameter, when comparing the stress relief method R-VSR with PWHT.

R-VSR reduce residual stresses in structures ${ }^{19}$, without generating PWHT problems ${ }^{7-20}$, to induce one or more vibratory states in a metal structure using eccentric vibrator and its associated power and control equipment ${ }^{21,22}$, attached to a structure supported on rubber blocks being free to vibrate. Such systems usually work in a frequency range between 0 and $100 \mathrm{~Hz}^{23}$. Vibration time may vary depending on the size and weight of the work piece ${ }^{21}$.

The equipment is switched on and tuned slowly up from zero to its maximum frequency $(0-100 \mathrm{~Hz})$. The structure's response is monitored and the resonance frequencies noted. The vibration is continued at the resonant frequency for approximately another 10 minutes. Times may vary depending on the size and weight of the piece ${ }^{21}$ and the material ${ }^{24}$.

Resonant vibrations are more efficient because the stresses are better distributed and, because they are low frequency vibrations, they carry high amplitude energy, significantly reducing residual stresses in metal and welded parts ${ }^{25}$.

Although R-VSR has advantages over PWHT, some questions to regarding its reliability in maintaining structural integrity of equipment remain unanswered. For example, it 
is not clear if the fracture toughness of welded joints relieved by resonant mechanical vibration is better than those relieved by treatment thermal.

For Luh and Hwang ${ }^{20}$ and Rao et al. ${ }^{22}$, the dynamic loads generated by inducing mechanical resonant vibrations in the component lead to a reduction of their residual stresses possibly due to the occurrence of dislocation movement and redistribution.

According to Walker et al. ${ }^{7}$, to reduce the residual stresses implies plastic deformation, usually in the form of intragranular microplastic processes as segments of single dislocations moving to low energy positions. The resonant vibration reduced the residual stresses in cold rolled carbon steel sheets by up to $40 \%$. Crisi and Mendonça ${ }^{21}$ concluded that the R-VSR relieved stresses of large structures and parts with fine dimensional tolerances.

By applying the R-VSR Luh and Hwang ${ }^{20}$ obtained a reduction of residual stresses in a sample welded and, according to Sun et al. ${ }^{18}$, it was valid for the relief of macro residual stresses in a pump shaft made of steel and replaced in PWHT welded sheet steel D6AC and D406A ${ }^{26}$.

Rao et al. ${ }^{22}$ developed a mathematical model to calculate the reduction of residual stresses, by submitting a base plate of HT-7U Tokamak to R-VSR, where the effectiveness of the treatment and the proposed model was evaluated in comparison to X-ray diffraction (XRD) analysis of stresses residuals.

Kwofie ${ }^{9}$ presented a model to simulate and characterize R-VSR through plastic deformation. Stress relief occurs when induced cyclic stresses added to residual stresses exceed the material's elastic limit.

The purpose of this paper was quantification the CTOD-fracture toughness in welded joints of Domex $700 \mathrm{MC}^{\circledR}$ steel sheets to evaluate the efficacy of vibration stress relief compared to thermal stress relief.
Residual stresses were measured in the Heat Affected Zone (HAZ) using XRD to compare and evaluate the two stress relief methods.

The stress relieving processes influence on the result of fracture toughness was assessed using CTOD tests. The tensile tests, metallographic and fractographic analysis were also used to characterize the efficiency between the R-VSR samples and the PWHT samples. Both treatments showed differences favorable to PWHT at all measured points by the XRD test, except at point "D" where residual stresses resulted in very close values. Tensile and CTOD tests presented advantage to the R-VSR at this point.

\section{Experimental procedure}

\subsection{Material}

DOMEX $700 \mathrm{MC}^{\mathrm{TM}}$ steel meets EN 10149-2 27 and is used in truck chassis, cranes and the railway industry ${ }^{28}$. The chemical composition was evaluated by optical emission spectroscopy (FOUNDRY-MASTER model Xline). Table 1 shows the resulting composition, are in accordance with the standard. Table 2 lists the expected mechanical properties of the material.

Steel plates $350 \mathrm{~mm}$ wide, $480 \mathrm{~mm}$ long and $9.6 \mathrm{~mm}$ thick were used as test specimens in this work. A chamfer was machined at $90 \mathrm{~mm}$ from the edge, perpendicularly to the lamination direction of the original plate; dimensions were selected in order to increase the effect of vibration on the welded joint (Figure 1). The plate used in the extension increased the bending moment and thus increased the deformation in the HAZ, as well as decreasing the natural frequency of the sample to values within the vibrator capacity.

Table 1. Chemical composition of Domex $700 \mathrm{MC}$ steel.

\begin{tabular}{|c|c|c|c|c|c|c|c|c|c|c|c|c|c|}
\hline $\mathrm{C}$ & $\mathrm{Si}$ & $\mathrm{Mn}$ & $\mathrm{P}$ & $\mathrm{S}$ & $\mathrm{Cr}$ & $\mathrm{Ni}$ & Mo & $\mathrm{V}$ & $\mathrm{Ti}$ & $\mathrm{Cu}$ & $\mathrm{Al}$ & $\mathrm{Nb}$ & $\mathrm{W}$ \\
\hline 0.079 & 0.04 & 2.10 & 0.011 & 0.003 & 0.027 & 0.033 & 0.078 & 0.011 & 0.1 & 0.027 & 0.045 & 0.05 & 0.015 \\
\hline
\end{tabular}

Table 2. Mechanical properties of Domex $700 \mathrm{MC}$ steel.

\begin{tabular}{cccccc}
\hline $\begin{array}{c}\text { Yield stress }(\mathrm{MPa}) \\
\min \end{array}$ & $\begin{array}{c}\text { Tensile strength } \\
(\mathrm{MPa}) \text { min }-\max \end{array}$ & Elongation until failure (\%) & \multicolumn{2}{c}{ Impact toughness } \\
\cline { 4 - 5 } 700 & $750-950$ & 10 & 12 & Temperature $\left({ }^{\circ} \mathrm{C}\right)$ & Energy $(\mathrm{J})$ \\
\cline { 3 - 5 }
\end{tabular}

Source: Adapted from High Strength Plates \& Profiles Inc ${ }^{23}$.

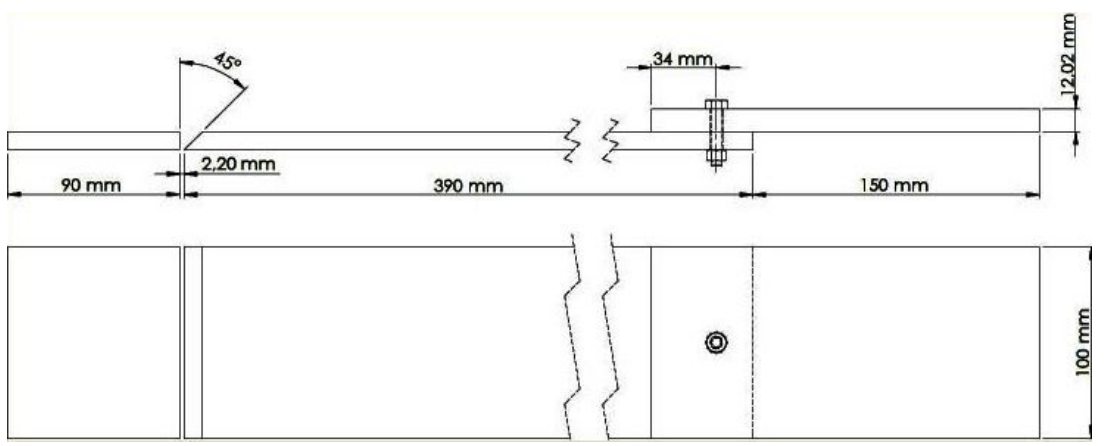

Figure 1. Dimensions of samples subjected to vibration with prolongation. 


\subsection{Welding parameters}

A root pass weld was carried out on the sheet followed by filling and finishing weld passes. The plate was cut into $100 \mathrm{~mm}$ wide sections and used as sample for vibration (see Figure 1). The parameters for MIG welding using the OTC Welding Robot, model AII-B4, mounted on a Sumig cells are in Table 3. Standard BS $7448^{29}$ and AWS D1.130, indicates using a half- $\mathrm{V}$ joint to make it easier for the crack tip to intercept significant amounts of coarse grain during the CTOD test. The solid wire is manufactured according to the standard Solid wire AWS 5.28/A5.28 $\mathrm{M}^{31}$.

\subsection{Calculation of natural frequency and elastic stress generated by deformation}

The lowest resonant frequency in a mode of vibration is the fundamental frequency of that mode ${ }^{32}$. For $\mathrm{Rao}^{24}$, the mass $(m)$ and the elastic constant $\left(k_{e q}\right)$ for swing beam with the load applied at the free end are the variables of Equation 1 which calculates analytically the natural frequency.

$$
w_{n}=\sqrt{\frac{k_{e q}}{m}} \quad(\mathrm{rad} / \mathrm{seg})
$$

The sample arranged with one degree of freedom (Figure 2) was crimped at one end and the other was free (cantilever beam $)^{33}$ in which the vibration produced oscillation in the vertical direction. Excitation was at the first natural frequency for that produced greater range and hence greater deformation.

The welded plate was instrumented in the HAZ with two unidirectional microextensometers model PA-06-040AB-120-LEN from Excel Sensors, placed on the same side of the plate, one at the point "C", $6 \mathrm{~mm}$ to the left of the weld center line and the other at the point " $\mathrm{D}$ ", $6 \mathrm{~mm}$ to the right of the weld center line (Figure 3), and this will be the designation used for the HAZ regions in evaluation. The spectrograms

Table 3. Parameters used in MIG welding.

\begin{tabular}{|c|c|c|c|}
\hline \multicolumn{4}{|r|}{ Welding Parameters } \\
\hline Chamfer size & & & Standard AWS D1.1; Angle: 45; Root opening: 2.2 mm; Top Joint: Half-V \\
\hline Protective gas & & & Argon with $16 \% \mathrm{CO} 2$; Flow rate: $161 / \mathrm{min}$ \\
\hline Solid wire & & & $\begin{array}{l}\text { ER90S-D2 Diameter: } 1.1 \mathrm{~mm} \text {; Material: low alloy steel; Trade name: LA-90; } \\
\text { Standard AWS 5.28 / A5.28M. }\end{array}$ \\
\hline \multirow{2}{*}{$\begin{array}{l}\text { Voltage, current and } \\
\text { metal transfer mode }\end{array}$} & \multirow{2}{*}{ Pass } & Root & 17.7 V and $170 \mathrm{~A}$ - Short Circuit \\
\hline & & Filling and finishing & $21.6 \mathrm{~V}$ and $150 \mathrm{~A}-$ Pulsed arc \\
\hline \multirow{2}{*}{ Speed } & \multirow{2}{*}{ Pass } & Root & $5.08 \mathrm{~m} / \mathrm{min}$ \\
\hline & & Filling and finishing & $5.334 \mathrm{~m} / \mathrm{min}$ \\
\hline
\end{tabular}

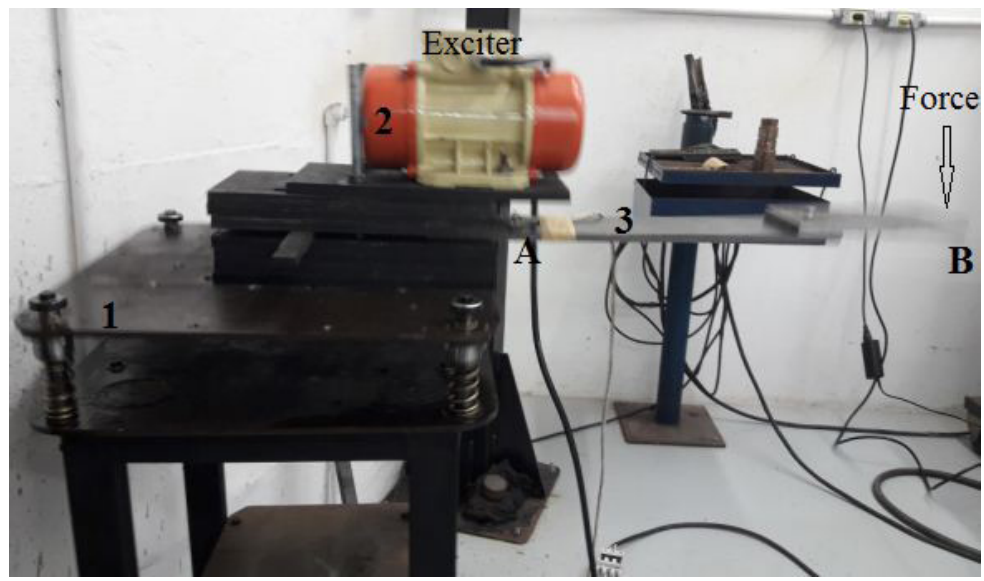

Figure 2. Vibration system: (1) Vibrating table, (2) Eccentric vibrator (Exciter), (3) Sample,

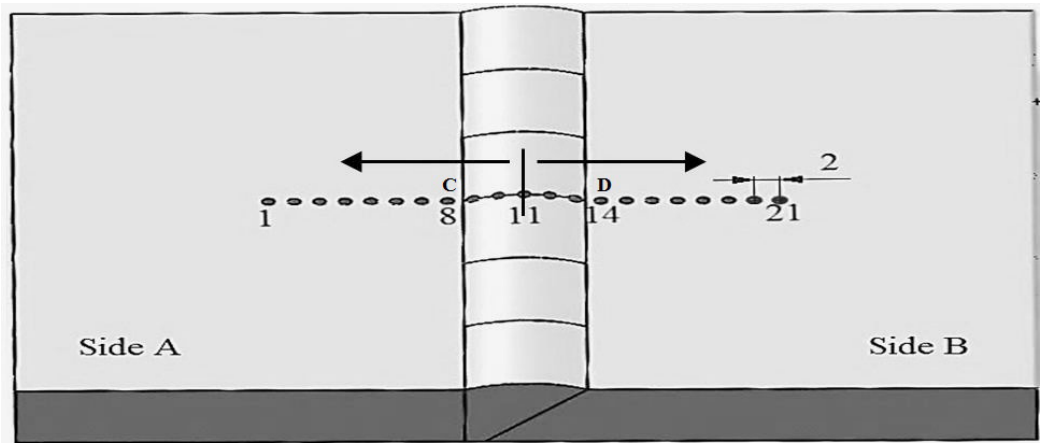

Figure 3. Representation of XRD measurement points in sample 1. 
generated in the Catman AP software allowed the visualization and analysis of the deformation levels while the sample was subjected to mechanical vibration. The elastic stress generated by the deformation measurements with the strain gauges during R-VSR, was calculated using the Hook's Law.

\subsection{Stress relief in resonant vibration}

The sample was excited by an eccentric vibrator MVL (Vibratory Machines Ltd.), model AR-12 - 100/36, attached to the sample with a holder that was solidary to the vibrating table, Figure 2. A frequency inverter WEG, model CFW-08, controlled the power supply and regulated the motor rotation. The vibration motion was applied transversely to the plate and the weld bead. The sample was designed in order to produce the greatest amplitude of vibration (and the greater deformation) at the HAZ "C" and "D" points.

The vibrator excites the sample subjected to R-VSR for 6 minutes after reaching the greatest deformation, Figure 2, from the region " $\mathrm{A}$ ", and when it reaches the resonance frequency it produces the highest amplitude at the free end "B" concentrating the applied force during the vibration in "B" which causes a reaction the extremity " $A$ " generating deformations around the welded region ${ }^{5}$.

\subsection{Stress relief from heat treatment - PWHT parameters}

The $\mathrm{SSAB}^{34}$ recommendations to avoid loss of steel properties are: the maximum heating rate is $100{ }^{\circ} \mathrm{C} / \mathrm{h}$, the time and immersion temperature are $2 \mathrm{~min} / \mathrm{mm}$ thick (minimum $30 \mathrm{~min}$ ) at $580{ }^{\circ} \mathrm{C}$ and maximum cooling rate is $100^{\circ} \mathrm{C} / \mathrm{h}$.

In this work, the sample was heated in the Jung muffle oven model 4212 to $300^{\circ} \mathrm{C}$ in one hour, then the heating was $100^{\circ} \mathrm{C}$ per hour to the temperature of $580^{\circ} \mathrm{C}$ remaining on this plateau for 40 minutes and was cooled to the oven. The thermal cycle used in the PWHT after welding is shown in the Figure 4.

\subsection{Measurement of residual stresses by diffraction $X$-ray}

A GE-SEIFERT Charon XRD M Research Edition diffractometer measured residual stresses. The sample was fixed in the goniometer in a way that weld bead was properly aligned with diffractometer measurement direction. The samples were fixed to an XYZ-automatized table that can change the sample position following a predetermined measurement strategy so each measurement point was positioned at the goniometer focus. The measurement direction could be automatically changed as the goniometer turns the sample to reach both longitudinal and transversal residual stressesand the position " 0 " of the focus was determined.

The software that conducts the diffractometer was configured by the parameters of Table 4 . The elastic constants used by the diffractometer software to calculate the residual stress: Young's modulus: $220264 \mathrm{MPa}$ and Poisson's ratio: 0.280.

The residual stress measurements were carried out before and after the stress relief. To ensure that the exact same positions were analyzed after and before the treatment, permanent positioning marks were made outside the analysis area. The value of the residual stresses varies from site to site in the same sample, so measuring the sample in the same locations made the results more expressive. Residual stresses were measured on each side of the strand separately, due to the deformation caused by welding the plates. First one side was measured and then the other was measured from the center of the weld bead. The arrows indicate the direction of measurement as shown in Figure 3.

First, the samples as welded were subjected to the analysis of residual stresses by X-ray diffraction next to points " $\mathrm{C}$ " and "D". After the first measurement, the samples, one at a time, were subjected to R-VSR applied transversely to the weld bead.

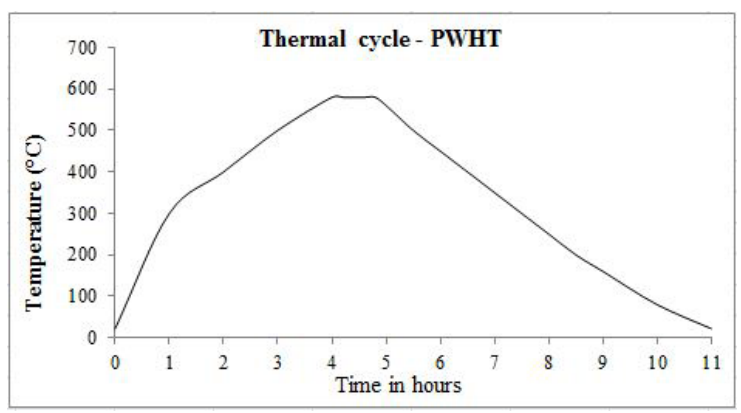

Figure 4. Thermal cycle for the treatment of Domex $700 \mathrm{MC}$ steel.

Table 4. Parameters used in the X-ray diffractometer.

\begin{tabular}{|c|c|}
\hline Parameters & Values \\
\hline X-ray tube element & $\mathrm{Cr}$ \\
\hline Wavelength $\mathrm{k}-\alpha$ & $2.2897 \AA$ \\
\hline Tube voltage & $30 \mathrm{kV}$ \\
\hline Tube Current & $50 \mathrm{~mA}$ \\
\hline Used detector & Meteor 1D \\
\hline Angles used in tangential and longitudinal directions & {$\left[-45^{\circ}\right.$ até $\left.+45^{\circ}\right]$, Chi $(\mathrm{x})=13$} \\
\hline Scan time per step & $15 \mathrm{~s}$ \\
\hline Step & $0.05^{\circ}$ \\
\hline Testing time: a measurement in one direction (Longitudinal) & $\sim 10$ minutes \\
\hline Diffraction peak used & $\left\{\begin{array}{lll}2 & 1 & 1\end{array}\right\}\{\mathrm{h} \mathrm{k} 1\}$ 2-Theta angle $\left[156.08^{\circ}\right]$ \\
\hline 2-theta range & {$\left[147^{\circ}-166^{\circ}\right]$} \\
\hline Collimator & $2 \mathrm{~mm}$ \\
\hline Filter & Vanadium \\
\hline
\end{tabular}




\subsection{Toughness test to fracture - CTOD}

The CTOD parameter was evaluated according to BS $7448^{29}$, ASTM E $1820^{35}$ and BS $7448^{36}$ standards. The specimens were tested under the following conditions: welded and relieved by PWHT and welded and relieved by R-VSR. The 5 CTOD specimens, Figure 5, were machined with a waterjet cutting machine, crosswise to the weld. The notches were machined with Wire Electrical discharge machining in the NQ orientation ${ }^{29}$ so that the fatigue crack grows in the coarse grain region located at point " $D$ ". The fatigue pre-crack opening followed the ASTM E1820 standard ${ }^{35}$. The frequency was $15 \mathrm{~Hz}$, the $\Delta \mathrm{K}$ was $16 \mathrm{MPa} \sqrt{\mathrm{m}}$ and the load ratio was $\mathrm{R}=0.1$. The calculation of the CTOD value in HAZ, from the maximum load, used the tensile properties of the base metal: $\sigma_{\mathrm{ys}}=794 \mathrm{MPa}$ and $\sigma_{\max }=821 \mathrm{MPa}$. After the CTOD test, the specimens were ruptured for fracture analysis.

The pre-crack opening and the CTOD test were performed on a MTS model 810 servo hydraulic machine with a 10 ton capacity, and a Flex Test controller. The MTS fracture extensometer model $632.02 \mathrm{~F}-20$ measured the crack growth to $\mathrm{a} / \mathrm{W}$ ratio of 0.5 through MTS Fracture Toughness TestWare software. The tests were performed at room temperature.

The pre-crack was measured on an ISIZ-Z3015 INSIZE profilometer. The fractography were analyzed by scanning electron microscope TESCAN, model VEGA-3 LM, to study the morphology and determine the mechanism of the fracture.

Metallographic analysis to locate the crack tip in fatigue after the CTOD assay followed the recommendations of standard BS7448 ${ }^{29}$. The specimens were sectioned along the thickness and prepared metallographically for analysis of the inner face of the median plane, using the ZEISS optical microscope, Axio Scope A.1.

\subsection{Tensile test}

Tensile tests were performed by a universal SCHENCK machine model UPM200 to know the values of yield strength, tensile strength and elongation, according to the ASTM $\mathrm{E} 8 \mathrm{M}^{37}$ standard, using 3 specimens for each condition evaluated. Three specimens were produced from Sample 1, relieved by PWHT, and 3 specimens were produced from Sample 0, relieved by R-VSR

\section{Results and Discussions}

\subsection{Calculation of natural frequency and deformation}

Table 5 lists the frequency values, the vibration time, the strain and the resulting stress.

\subsection{Analysis of residual stresses measured by $X$-ray diffraction}

Figure 6 shows the residual stress values of samples produced after welding, without the residual stress relief treatments. The measurements showed compressive residual stresses in the base metal and tensile stresses in the HAZ and addition metal. The same condition was found in Marques et al. ${ }^{1}$ where residual stresses become compressive in the regions furthest from the weld while in the weld bead and HAZ the stresses are tractive.

The residual stress profiles found in sample 0 and sample 1 are similar, Figure 6, and the difference in residual stress values after welding between the two samples was $52.23 \mathrm{MPa}$ at point "C" and 19.86 MPa at point "D", because the plate were not exactly equal in flatness and the welding robot

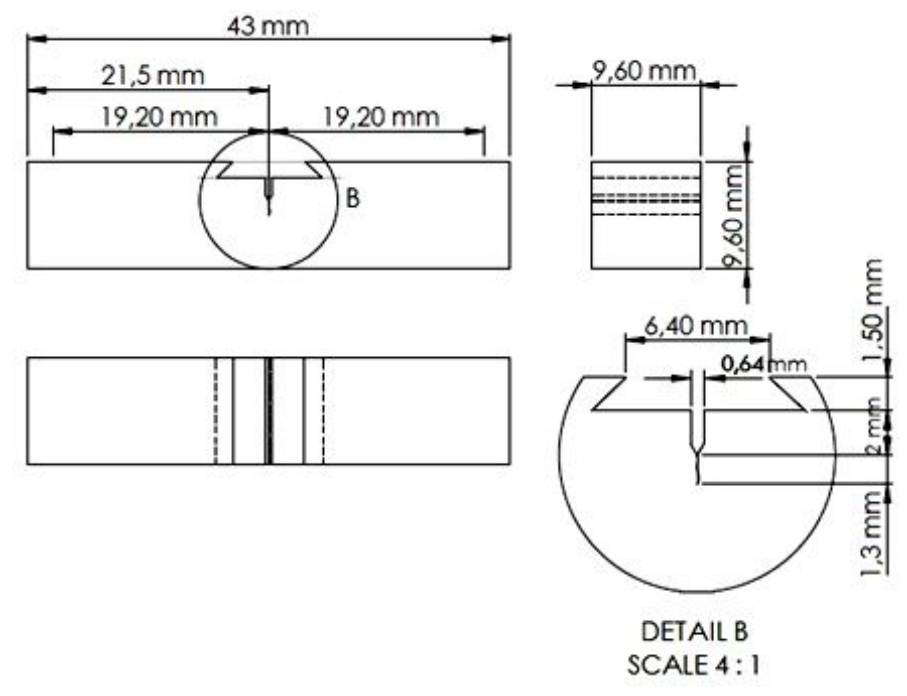

Figure 5. Single Edge Bend $[\mathrm{SE}(\mathrm{B})]$ specimen for the CTOD test.

Table 5. Stress as a function of strain measured by strain gauges attached the HAZ.

\begin{tabular}{ccccccc}
\hline \multirow{2}{*}{ Sample } & \multirow{2}{*}{ Strain gauge } & \multirow{2}{*}{ Time $(\mathrm{s})$} & \multirow{2}{*}{ Strain $(\mu \mathrm{m} / \mathrm{m})$} & \multicolumn{2}{c}{ Frequency $(\mathrm{Hz})$} & \multirow{2}{*}{ Stress $(\mathrm{MPa})$} \\
\cline { 5 - 7 } Sample 0 & 1 & 600 & 900 & 27.32 & 28.13 & 198.24 \\
\cline { 2 - 6 } & 2 & 600 & 980 & 27.32 & 28.13 & 215.86 \\
\hline
\end{tabular}


did not compensate for the distance between the electrode and the plate; the samples were produced with different dimensions in width and length before measuring the residual stresses and, according to $\mathrm{Hauk}^{38}$, may be influenced by the manufacturing processes of the plates and the chamfer.

Results for sample 1 after PWHT, Figure 7, present a reduction of residual stresses both in the base metal and in the HAZ. The average residual stress at point "C" of the sample as welded was 169.60 MPa and at point "D" it was 194.63 MPa. After relieving, the average values decreased to $3.73 \mathrm{MPa}$ at point "C" and 11.63 MPa at point "D".

After PWHT the weld bead continued with average residual stresses of $100 \mathrm{MPa}$ in the center of the bead and, as explained in ${ }^{11}$ due to the high heat input in the weld metal causing greater thermal expansion and, as a consequence, it presented the highest residual stresses.

Comparing surface residual stresses measured by XRD in the HAZ of sample 0 as-welded and after R-VSR conditions, Figure 7, was found at the point " $D$ " a reduction in the values from 174.77 $\mathrm{MPa}$ to $24.40 \mathrm{MPa}$, because this was the sample region that most deformed during mechanical vibration process, according to data in Table 5.
At point "C" of $\mathrm{HAZ}$, the values before and after the relief were $117.37 \mathrm{MPa}$ and $123.93 \mathrm{MPa}$ respectively. In this case, it is possible to consider that the elastic stress of 198.24 MPa (Table 5) generated by the deformation, when added to the residual stress of $117.37 \mathrm{MPa}$, was not sufficient to reach the yield stress value at that point and, according to Walker et al. ${ }^{7}$, to reduce residual stress, plastic deformation is required.

When comparing the two methods, the average surface residual stress for the relieved samples showed that PWHT is more effective than R-VSR in reducing the levels of residual compressive and tensile stress, considering the extent measured by the DRX. However, when it focuses on the HAZ "D" point where the highest stress was induced during vibration, the average surface residual stress results after relief were 11.63 $\mathrm{MPa}$ to PWHT and 24.4 MPa to R-VSR (Figure 7), showing that at this point the effectiveness was similar.

The time and force that must be applied during the vibration depends on the size and shape of the sample ${ }^{21}$. There is a possibility that one or both of these factors did

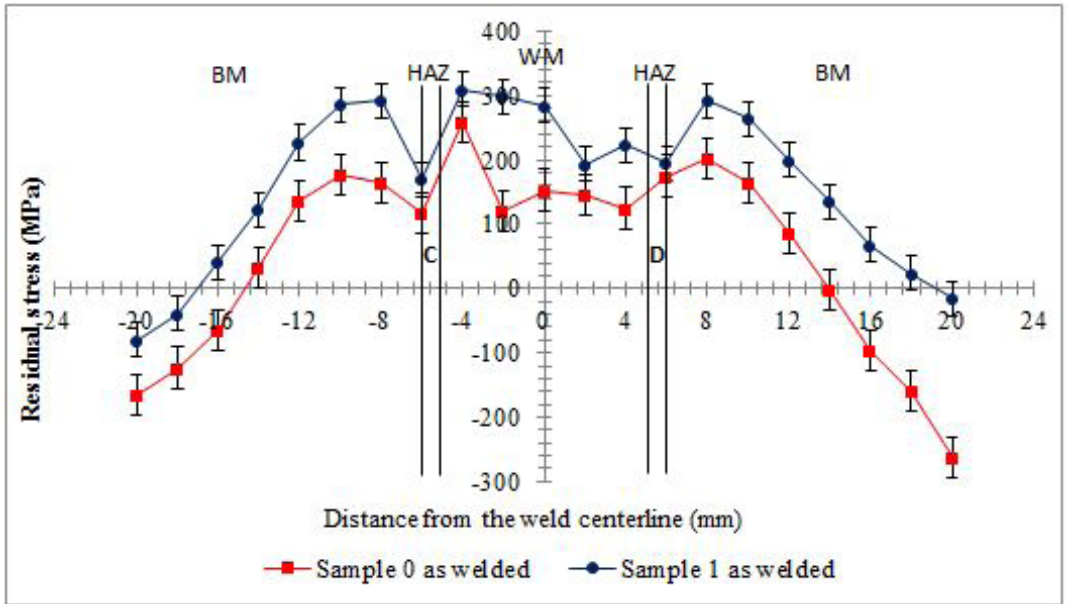

Figure 6. Comparative values of the residual stresses between samples 0 and 1 as welded. Solid lines indicate the extent of the weld bead and HAZ.

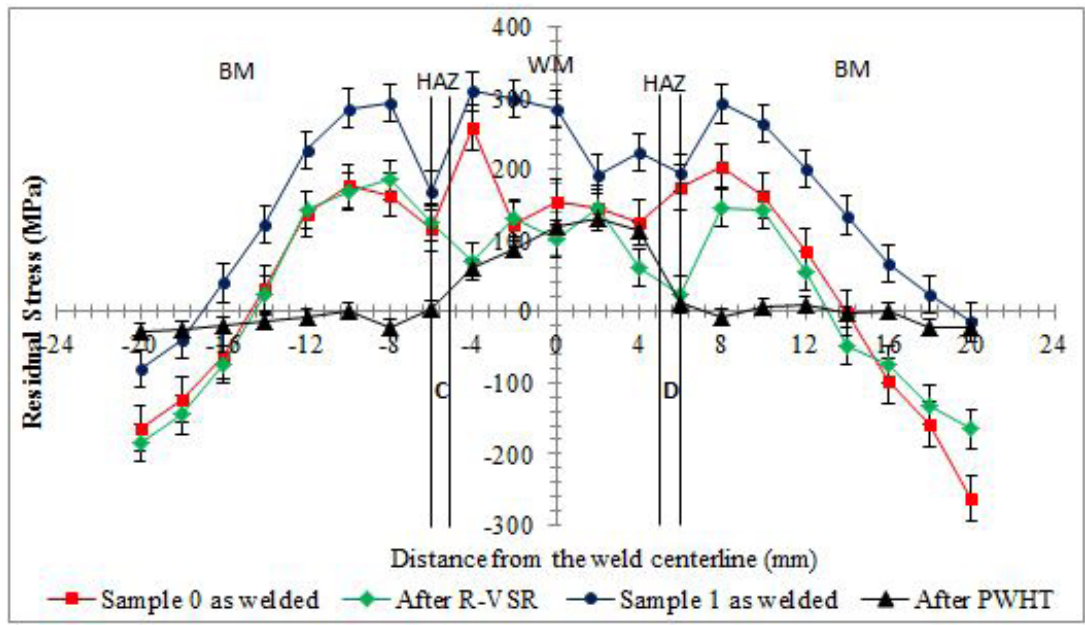

Figure 7. Comparative values of the residual stresses between samples as welded, sample 1 relieved by PWHT and sample 0 relieved by R-VSR. Solid lines indicate the extent of the weld bead and HAZ. 
not reach the appropriate value to produce stress relief over the entire length of the sample measured by XRD.

\subsection{Analysis of the comparison between residual stresses and FWHM}

Full width at half maximum (FWHM) is the parameter of a curve or function relative to its width and is given by the difference between two extreme values of a free variable in which the function reaches half of the maximum value $^{39}$. For Banazwski ${ }^{40}$, higher values of FWHM in XRD measurements indicate more plastic deformation, and are an indication of distortion ${ }^{38}$.

Figure 8 a show results for the sample 1 which was stress relieved through PWHT; XRD measured residual stress and FWHM values before and after the stress relief process are shown. The FWHM values varied significantly, indicating that there was substantial distortion during the process.

Figure $8 \mathrm{~b}$ shows the results of the FWHM for sample 0 relieved by the vibration process. Although stress levels are only reduced more noticeably at point " $D$ " of the weld profile, FWHM values remain relatively constant throughout the profile, indicating that less distortion occurred during this process.

\subsection{Analysis of fracture toughness test - CTOD}

Table 6 presents the data for the CTOD calculation. The differences found are of the yield limit of the as welded material and relieved by PWHT and R-VSR.

The criteria for validating the test are based on the crack size. The specimen V1 did not meet the standard BS7448 ${ }^{36}$, because it varied $23.69 \%$ between the smallest and largest measure in the HAZ, so the result for this sample have therefore been discarded.

From the results of the fracture toughness tests presented in Table 7, it is possible to observe the CTOD values presented a bigger resistance to crack propagation in samples relieved by resonant mechanical vibration, being, on average, $36.73 \%$ higher than heat treated samples.

This difference in CTOD values, Table 8, when comparison the two residual stress relief methods, is initially related to the crack opening region identified in the micrographic analysis and the fracture type (Figure 9) identified in the fractographic analysis. It is known that the HAZ is formed by very small regions that can have significant variations in fracture toughness, as shown in Table 8. These small regions make it difficult for the machining of the notch, to generate the pre-crack in the specimens, to occur always in the same place.

The crack opening region at HAZ determined the differences in the comparison of CTOD values between the R-VSR and PWHT method, it was also important to observe the more homogeneous behavior of the R-VSR method because, although the pre-crack is located in different regions, the differences found were less significant than in PWHT, based on the values of standard deviation, which was 0.045 for R-VSR and 0.085 for PWHT.

The fracture occurred due to microvoid coalescence in all samples relieved by R-VSR, regardless of the region being fine grains or coarse grains. For T1 and T5 samples, relieved by PWHT, the fracture was also caused by microvoids coalescence, justifying the small difference in CTOD values when compared to vibrated samples.
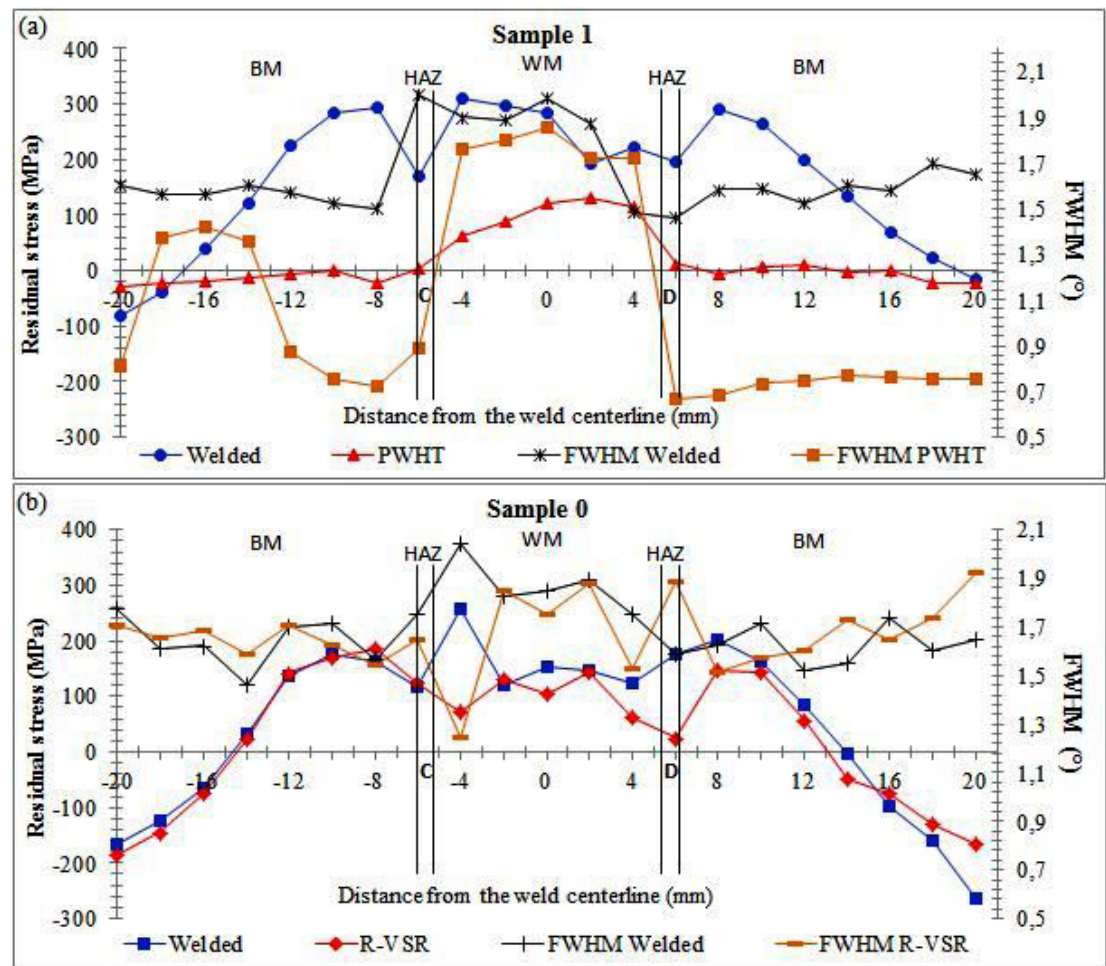

Figure 8. (a) Comparison between FWHM and transverse residual stresses measured in the sample 1. (b) Comparison between FWHM and transverse residual stresses measured in the sample 0. Solid lines indicate the extent of the weld bead and HAZ. 
Table 6. Domex $700 \mathrm{MC}$ steel data for CTOD calculation.

\begin{tabular}{lccc}
\hline \multicolumn{1}{c}{ Material Data } & \multicolumn{3}{c}{ Condition } \\
\cline { 2 - 4 } & Welded & PWHT & R-VSR \\
\hline Elasticity Modulus $(\mathrm{E})[\mathrm{MPa}]$ & 220264 & 220264 & 220264 \\
\hline Yield point, $\left(\sigma_{\mathrm{YS}}\right.$ ou $\left.\mathrm{R}_{\mathrm{p} 0,2}\right)[\mathrm{MPa}]$ & 610.65 & 632.45 & 687.91 \\
\hline Resistance Limit, $\left(\sigma_{\mathrm{UTS}}\right.$ ou $\left.\mathrm{R}_{\mathrm{m}}\right)[\mathrm{MPa}]$ & 732.65 & 732.86 & 732.54 \\
\hline Poisson's ratio $(v)$ & 0.28 & 0.28 & 0.28 \\
\hline Material's type & $\mathrm{HAZ}$ & $\mathrm{HAZ}$ & HAZ \\
\hline
\end{tabular}

Table 7. CTOD test results of the evaluated conditions.

\begin{tabular}{|c|c|c|c|c|c|c|c|c|}
\hline Region & Condition & Specimen & Strength $(\mathrm{N})$ & $\mathrm{Vp}(\mathrm{mm})$ & CTOD (mm) & Average & $\begin{array}{r}\text { Standard } \\
\text { deviation }\end{array}$ & Curve Type \\
\hline \multirow{9}{*}{ HAZ } & \multirow{5}{*}{ PWHT } & $\mathrm{T} 1$ & 5439.03 & 1.45665 & 0.309 & \multirow{5}{*}{0.219} & \multirow{5}{*}{0.085} & $\mathrm{~V}$ \\
\hline & & $\mathrm{T} 2$ & 5987.02 & 0.625296 & 0.157 & & & III \\
\hline & & T3 & 6407.67 & 0.510771 & 0.160 & & & III \\
\hline & & $\mathrm{T} 4$ & 5454.11 & 0.529804 & 0.155 & & & III \\
\hline & & $\mathrm{T} 5$ & 5221.64 & 1.191036 & 0.316 & & & $\mathrm{~V}$ \\
\hline & \multirow{4}{*}{ R-VSR } & $\mathrm{V} 2$ & 5922.84 & 1.01208 & 0.314 & \multirow{4}{*}{0.300} & \multirow{4}{*}{0.045} & $\mathrm{~V}$ \\
\hline & & $\mathrm{V} 3$ & 4490.47 & 0.986473 & 0.244 & & & $\mathrm{~V}$ \\
\hline & & V4 & 5032.53 & 1.029942 & 0.289 & & & $\mathrm{~V}$ \\
\hline & & V5 & 4661.01 & 1.361096 & 0.353 & & & $\mathrm{~V}$ \\
\hline
\end{tabular}

Table 8. Relationship between CTOD value, microstructure and fracture type after residual stress relief.

\begin{tabular}{cccc}
\hline Specimen & CTOD $(\mathrm{mm})$ & Crack opening region & Fracture Type \\
\hline T1 & 0.309 & Fine grains & Microvoids coalescence \\
\hline T2 & 0.157 & Coarse grains & Cleavage \\
\hline T3 & 0.160 & Coarse grains & Cleavage \\
\hline T4 & 0.155 & Addition metal & Microvoids coalescence \\
\hline T5 & 0.316 & Addition metal & Microvoids coalescence \\
\hline V2 & 0.314 & Fine grains & Microvoids coalescence \\
\hline V3 & 0.244 & Fine grains & Microvoids coalescence \\
\hline V4 & 0.289 & Fine grains & Microvoids coalescence \\
\hline
\end{tabular}

T1

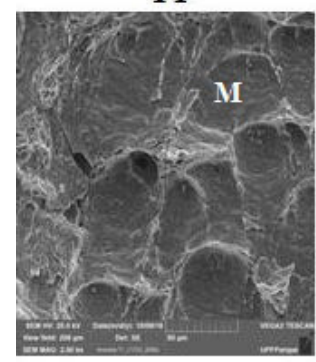

T2

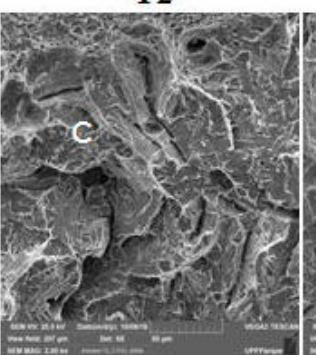

T3

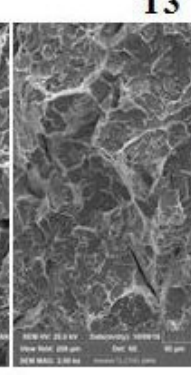

T4

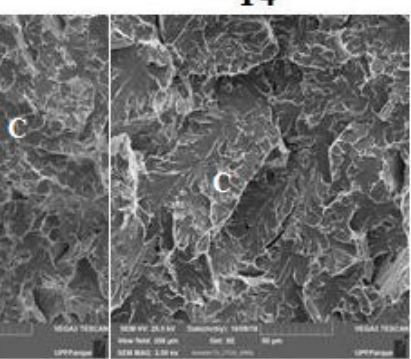

T5

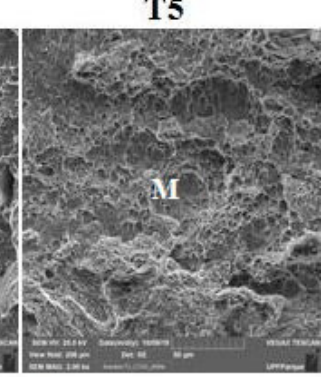

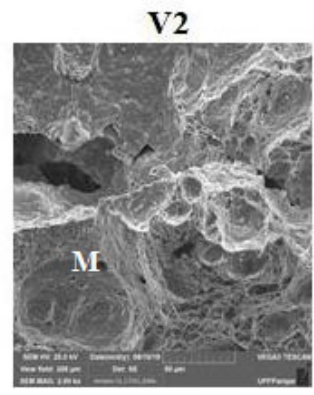

V3

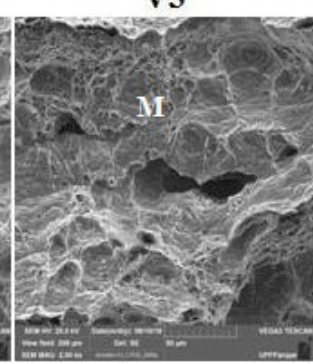

V4

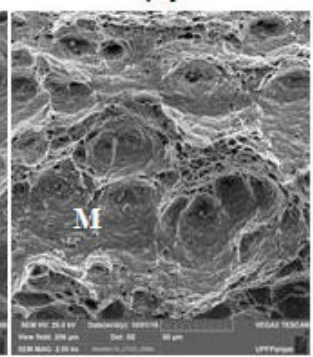

V5

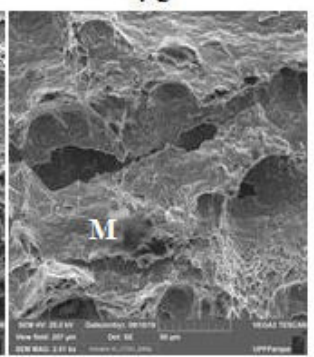

Figure 9. Fracture types found in the fractographic analysis for specimens relieved by heat treatment (T) and vibration (V), where M (Microvoids) and C (Cleavage). 
Table 9. Tensile test result for samples relieved by PWHT and R-VSR.

\begin{tabular}{|c|c|c|c|c|c|c|c|}
\hline & & \multicolumn{3}{|c|}{ Specimen } & \multirow{2}{*}{ Average } & \multirow{2}{*}{$\begin{array}{l}\text { Standard } \\
\text { deviation }\end{array}$} & \multirow{2}{*}{$\begin{array}{c}\text { Average } \\
\text { elongation }\end{array}$} \\
\hline & & 1 & 2 & 3 & & & \\
\hline \multirow[t]{2}{*}{ Sample 1 PWHT } & Yield stress $(\mathrm{MPa})$ & 636.58 & 624.89 & 635.88 & 632.45 & 6.56 & \multirow[t]{2}{*}{$6.15 \%$} \\
\hline & Tensile strength $(\mathrm{MPa})$ & 736.09 & 724.57 & 737.91 & 732.86 & 7.23 & \\
\hline \multirow[t]{2}{*}{ Sample 0 R-VSR } & Yield stress $(\mathrm{MPa})$ & 695.90 & 668.63 & 699.20 & 687.91 & 16.78 & \multirow[t]{2}{*}{$4.39 \%$} \\
\hline & Tensile strength (MPa) & 757.27 & 713.37 & 726.99 & 732.54 & 22.47 & \\
\hline
\end{tabular}

Comparing V5 with T2 and T3, Table 8, where the crack opening was in the coarse-grained region, there is a fracture by microvoids coalescence in $\mathrm{V} 5$ and a fracture by cleavage in T2 and T3, justifying the difference greater than $100 \%$ in the CTOD for the specimens relieved by R-VSR.

It should be noted that the CTDO test took place at point " $\mathrm{D}$ ", in the middle section of the specimen at a distance of approximately $4.8 \mathrm{~mm}$ from the surface. The subsurface residual stresses were not measured at this depth, so it is possible that there are inaccuracies regarding the influence of the residual stresses relief measured by XRD on the results of the CTOD test.

For more reliable results, Javadi et al. ${ }^{41}$, have indicated the use of several methods to measure residual stresses, since a greater number of independent techniques allow a more reliable characterization of residual stresses, including in this list the techniques used to measure subsurface residual stresses such as: neutron diffraction, incremental deep hole drilling and incremental centre hole drilling, which could more accurately assess the effectiveness of the R-VSR and PWHT methods in the result of fracture toughness.

The generated deformations during the R-VSR were measured on the surface close to the "C" and " $\mathrm{D}$ " points in the HAZ of sample 0 and produced elastic stresses in the entire cross-section which, added to the residual stresses, caused stress relief in this region, however, the magnitude of these deformations was not measured at point " $D$ " where the CTOD test started, so it is acceptable to state that there was some stress relief and that these influenced the CTOD results, however it was not possible to quantify the extent of this relief. Similarly, these considerations are also valid for PWHT.

\subsection{Analysis of tensile test}

The results of the tensile tests, Table 9 , show for R-VSR (sample 0 ) an average value for the yield stress of $55.46 \mathrm{MPa}$ or $8.77 \%$ greater than PWHT (sample 1), while for both methods the average value for tensile strength was $732 \mathrm{MPa}$. According to Walker et al. ${ }^{7}$, the R-VSR relieves residual stresses without changing mechanical properties, unlike what occurs in PWHT. For Crisi and Mendonça ${ }^{21}$ heat treatment decreases tensile strength but increases elongation.

\section{Conclusions}

The study quantified the residual stress relief measured by $\mathrm{X}$-ray diffraction and its relationship to the elastoplastic fracture toughness in the Heat Affected Zone of Domex $700 \mathrm{MC}^{\circledast}$ steel welded joints, comparing the effectiveness between R-VSR and PWHT stress reliefs, concluding that: a) Residual stresses measured by XRD in the samples as welded showed compressive residual stresses in the base metal and tensile stresses in the HAZ and filler metal. As expected, the PWHT was effective in reducing the residual stress substantially.

b) For the R-VSR method the residual stresses results measured by X-ray diffraction at point " $\mathrm{C}$ " were less effective, but at point " $D$ ", where the elastic stress generated by the deformation was higher, the result was a residual stress relief very close to that achieved by the PWHT method.

c) FWHM values for PWHT samples varied significantly through the profile, indicating that this process leads to significant distortion. FWHM for R-VSR samples was relatively constant throughout the profile, indicating that less distortion was induced, despite the non-uniform stress relief seen in residual stress profiling.

d) The reduction in residual stresses was less significant at point "D", however the fracture toughness tests presented the best results for stress relief by R-VSR, where the average CTOD values were $36.73 \%$ higher than the values resulting from the application of stress relief by PWHT.

e) In the tensile test, stress relief by R-VSR was more effective in producing less change in mechanical properties than stress relief by PWHT.

f) It is recommended to use different techniques to measure subsurface residual stresses to make the relationship of stress relief with the R-VSR and PWHT methods and their influences on the results of the CTOD test more accurate.

\section{References}

1. Marques PV, Modenesi PJ, Bracarense AQ. Soldagem, fundamentos e tecnologia. 3. ed. Belo Horizonte: UFMG; 2011.

2. Rossini NS, Dassisti M, Benyounis KY, Olabi AG. Methods of measuring residuals stresses in components. Mater Des. 2012;35:572-88. http://dx.doi.org/10.1016/j.matdes.2011.08.022.

3. Leggatt RH. Residuals stresses in welded structures. Int J Press Vessels Piping. 2008;85(3):144-51. http://dx.doi.org/10.1016/j. ijpvp.2007.10.004.

4. Totten G, Howes M, Inoue T. Handbook of residuals stress and deformation of steel. 1st ed. Materials Park: ASM International; 2002.

5. Aoki S, Nishimura T, Hiroi T, Hirai S. Reduction method for residuals stress of welded joint using harmonic vibrational load. Journal of Nuclear Engineering and Design. 2007;237(2):20612. http://dx.doi.org/10.1016/j.nucengdes.2006.06.004. 
6. ASM International. Handbook of welding, brazing and soldering: residuals stresses and distortion. Materials Park: ASM International; 1993.

7. Walker CA, Waddell AJ, Johnston DJ. Vibratory stress relief: an investigation of the underlying processes. Proc Inst Mech Eng, E J Process Mech Eng. 1995;209(1):51-8. http://dx.doi. org/10.1243/PIME_PROC_1995_209_228_02.

8. Xu J, Chen L, Ni C. Effect of vibratory weld conditioning on the residuals stresses and distortion in multipass girth-butt welded pipes. Int J Press Vessels Piping. 2007;84(5):298-303. http://dx.doi.org/10.1016/j.ijpvp.2006.11.004.

9. Kwofie S. Plasticity model for simulation, description and evaluation of vibratory stress relief. Mater Sci Eng A. 2009;516(12):154-61. http://dx.doi.org/10.1016/j.msea.2009.03.014.

10. Baqar SAR, Jain YR, Khanna P. Vibratory stress relief techniques: a review of present trends and future prospects. Int J Emerg Technol Adv Eng. 2014;4(11):141-4.

11. Dong P, Song S, Zhang J. Analysis of residual stress relief mechanisms in post-weld heat treatment. Int J Press Vessels Piping. 2014;122:6-14. http://dx.doi.org/10.1016/j.ijpvp.2014.06.002.

12. Fernandes JR, Batista GZ, Morales EV, Bott IS. Efeito do tratamento térmico de alívio de tensões na microestrutura e propriedades de um tubo API 51 X65MS. Tecnol Metal Mater Min. 2016;13(4):356-64. http://dx.doi.org/10.4322/2176-1523.1125.

13. Chuvas TC, Garcia PSP, Pardal JM, Fonseca MPC. Influence of heat treatment in residual stresses generated in P91 steelpipe weld. Mater Res. 2015;18(3):614-21. http://dx.doi. org/10.1590/1516-1439.006315.

14. Sadeghi B, Sharifi H, Rafiei M, Tayebi M. Effects of post weld heat treatment on residual stress and mechanical properties of GTAW: the case of joining A537CL1 pressure vessel steel and A321 austenitic stainless steel. Eng Fail Anal. 2018;94:396-406. http://dx.doi.org/10.1016/j.engfailanal.2018.08.007.

15. Aoki S, Nishimura T, Hiroi T. Reduction method for residuals stress of welded joint using random vibration. Journal of Nuclear Engineering and Design. 2005;235(14):1441-5. http://dx.doi. org/10.1016/j.nucengdes.2005.02.005.

16. Aoki S, Nishimura T, Hiroi T. Reduction method for residuals stress of welded joint using harmonic vibrational load. Journal of Nuclear Engineering and Design. 2007;237(2):206-12. http:// dx.doi.org/10.1016/j.nucengdes.2006.06.004.

17. Adams CM, Klauba BB, Barry JT. Vibratory stress relief: methods used to monitor and document effective treatment, a survey of users and directions for further research. In: ASM Proceedings of the International Conference: Trends in Welding Research; 2005; Pine Mountain, Georgia, USA. Materials Park: ASM International; 2005. p. 601-606.

18. Sun MC, Sun YH, Wang RK. Vibratory stress relieving of welded sheet steels of low alloy high strength steel. Mater Lett. 2004;58(7-8):1396-9. http://dx.doi.org/10.1016/j. matlet.2003.10.002.

19. Dawson R, Moffat DG. Vibratory stress relief: a fundamental study of its effectiveness. J Eng Mater Technol. 1980;102(2):16976. http://dx.doi.org/10.1115/1.3224793.

20. Luh GC, Hwang RM. Evaluating the effectiveness of vibratory stress relief by a modified hole-drilling method. Int J Adv Manuf Technol. 1998;14(11):815-23. http://dx.doi.org/10.1007/BF01350766.

21. Crisi GS, Mendonça DP. Stress relief of welds by heat treatment and vibration: a comparison between the two methods. 2006 [access 28 april 2016]. Available from: http://www.vsrtechnology. net/stress-relief-of-welds/

22. Rao D, Wang D, Chen L, Ni C. The effectiveness evaluation of 314L stainless steel vibratory stress relief by dynamic stress. Int J Fatigue. 2007;29(1):192-6. http://dx.doi.org/10.1016/j.jifatigue.2006.02.047.
23. Lindqvist S, Holmgren J. Alternative methods for heat stress relief [thesis master]. Luleå: Department of Applied Physics and Mechanical Engineering, Division of Manufacturing Systems Engineering, University of Technology; 2007.

24. Rao SS. Vibrações mecânicas. 4. ed. São Paulo: Pearson Education do Brasil; 2014.

25. Claxton R. Vibratory stress relief: an authoritative overview. Melbourne: Material Australia; 1998. [access 20 june 2016]. Available from: http://documents.mx/documents/vibratorystress-relief-.html\#

26. Sun MC, Sun YH, Wang RK. The vibratory stress relief of a marine shafting of $35^{\#}$ bar steel. Mater Lett. 2004;58(3-4):299303. http://dx.doi.org/10.1016/S0167-577X(03)00473-7.

27. British Standard. BS EN 10149-2: hot rolled flat products made of high yield strength steels for cold forming. Part 2: Technical delivery conditions for thermomechanically rolled steels. Brussels: European Standard; 2013.

28. High Strength Plates \& Profiles Inc. Domex $700 \mathrm{MC}$ Hot rolled, extra high strength, cold forming steel. 2018. [access 4 april 2018]. Available from: www.highstrengthplates.com/ images/ pdfs/Domex_700_MC.pdf

29. British Standard - BS. BS 7448 part 2: method for determination of $K_{\mathrm{Ic}}$, critical CTOD and critical $J$ values of welds in metallic materials. London: British Standard; 1997.

30. American Welding Society - AWS. AWS D1.1M: structural welding code: steel. Miami: AWS; 2010.

31. American Welding Society - AWS. AWS A5.28/A5.28M: specification for low-alloy steel electrodes and rods for gas shielded arc welding. Miami: AWS; 2005.

32. American Society for Testing and Materials - ASTM. ASTM E1876: standard test method for dynamic young's modulus, shear modulus, and Poisson's ratio by impulse excitation of vibration. West Conshohocken: ASTM International; 2001.

33. Steidel RF Jr. Free vibration of an undamped translational system. In: Rao SS, editor. Mechanical vibrations. 5th ed. New Jersey: Pearson Education; 2011. p. 129-142.

34. SSAB. Welding of Domex. 2018. [access 17 june 2018]. Available from: https://www.ssab.com.br/products/brands/ strenx/products/strenx-700-mc?accordion=order_and_delivery

35. American Society for Testing and Materials $-\overline{A S T M}$. ASTM E1820: standard test method for measurement of fracture toughness. West Conshohocken: ASTM International; 2014.

36. British Standard-BS. BS 7448 part 1: method for determination of $K_{\mathrm{Ic}}$, critical CTOD and critical $J$ values of metallic materials. London: British Standard; 1991.

37. American Society for Testing and Materials - ASTM. ASTM E8M: standard test methods for tension testing of metallic materials. West Conshohocken: ASTM International; 2013.

38. Hauk V. Structural and residual stress analysis by nondestructive methods. 1st ed. Amsterdam: Elsevier Science; 1997.

39. Bielefeldt RSC, Diehl IL, Clarke TGR. Análise do alívio térmico de tensões residuais do aço SAE 4140 por difração de raios- $x$ fast in-situ. In: Proceedings of the 72nd ABM Annual Congress; 2017 Oct 2-6; São Paulo, Brasil. São Paulo: ABM; 2017. p. 2808-2821. http://dx.doi.org/10.5151/1516-392X-30775.

40. Banazwski BJ. Using X-ray diffraction to assess residual stresses in laser peened and welded aluminum [Master thesis]. Monterey: Naval Postgraduate School; 2011.

41. Javadi Y, Smith MC, Abburi Venkata K, Naveed N, Forsey AN, Francis JA, et al. Residual stress measurement round robin on an electron beam welded joint between austenitic stainless steel 316L(N) and ferritic steel P91. Int J Press Vessels Piping. 2017;154:41-57. http://dx.doi.org/10.1016/j. ijpvp.2017.06.002. 